Cases of nefopam overdose followed up by National Poisons Information Service or reported to manufacturer. All patients were discharged within 24 hours or remained longer in hospital for psychiatric or social reasons

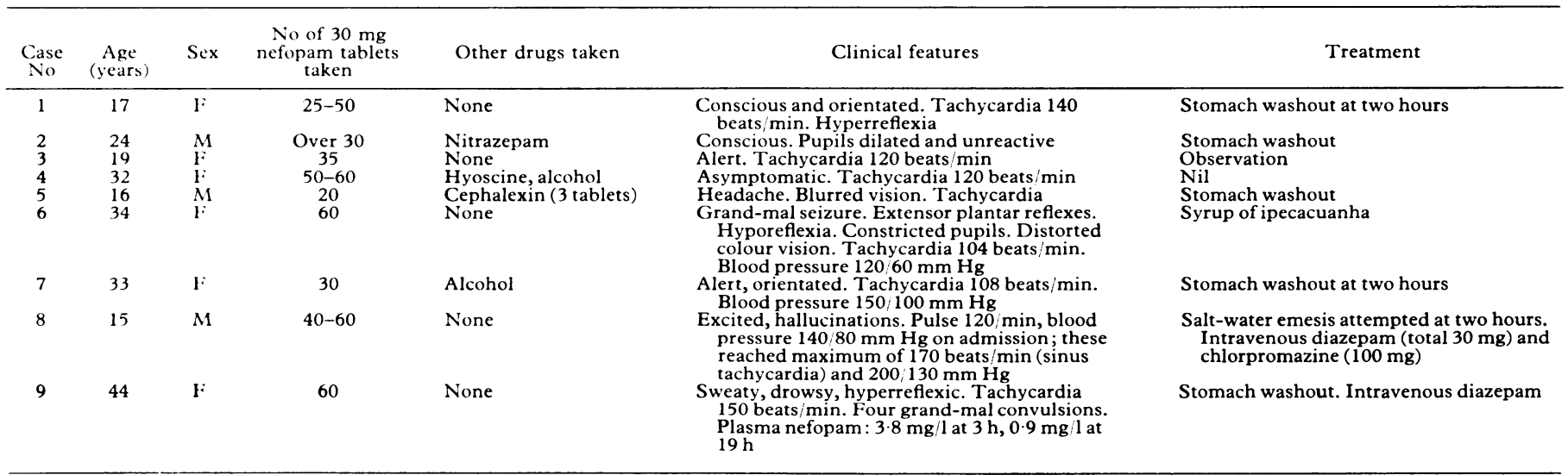

with a hyperdynamic circulation are the principal cardiovascular complications. In case 4 hyoscine may have contributed to the tachycardia, and in case 8 a salt-water emesis may have contributed to hypertension; the dangers of this procedure are known. ${ }^{4}$

All patients recovered uneventfully with routine supportive treatment, which suggests that nefopam is fairly safe when taken in overdose. Since there is no specific antidote for nefopam poisoning, treatment should be directed primarily to the prompt removal of ingested drug by gastric lavage together with control of convulsions and hallucinations; diazepam would appear to be effective for this purpose, and beta-adrenergic blockade might help to control the cardiovascular complications.

We thank Dr ' $\mathrm{T}$ W G Kinnear, Hull Royal Infirmary, and Dr Philip Science, HM Coroner for North Humberside, for permission to report this case; Mrs H Court for compiling data; and Dr H E Lewis, Carnegie Medical, for helpful discussions. Mass spectrometry was carried out by Dr M Whitehouse of the Metropolitan Police Forensic Science Laboratory.

Requests for reprints to: Dr J A Henry, Poisons Unit, New Cross Hospital, London SE14 5ER.

${ }^{1}$ Heel RC, Brogden RA, Pakes GE, Speight TM, Avery GS. Nefopam: a review of its pharmacological properties and therapeutic efficacy. Drugs $1980 ; 19 \cdot 249-67$

${ }^{2}$ Case MT, Smith JK, Nelson RA. Chronic oral toxicity studies of nefopam hydrochloride in rats and dogs. Toxicol Appl Pharmacol 1976;36:301-6.

${ }^{3}$ Case MT, Smith JK, Nelson RA. Chronic oral toxicity studies of nefopam hydrochloride in rats and dogs. Toxicol Appl Pharmacol 1975;33:46-51.

4 Goulding R, Volans GN. Emergency treatment of common poisons: emptying the stomach. Proc $R$ Soc Med 1977;70:766-70.

(Accepted 14 September 1981)

Castle Hill Hospital, Cottingham, North Humberside HU16 5QJ

D M PIERCY, MB, MRCPATH, consultant pathologist

Hull Royal Infirmary, Hull HU3 2JZ

J A CUMMING, MB, Снв, house physician

Poisons Unit, Guy's Hospital, London SE1 9RT

SHEILA DAWLING, BSC, biochemist

J A HENRY, MB, MRCP, senior registrar in intensive care and toxicology

\section{Re-emergence of bullous impetigo}

In common with other maternity departments, neonatal bullous impetigo (pemphigus neonatorum) has been seen only sporadically at this hospital over the past 10 years. Recently, however, 10 cases were seen in term infants on several postnatal wards. Rather than an outbreak originating from a single source, this appeared to have been a cluster of separate cases, as several different phage types were identified.

\section{Patients, methods, and results}

During the seven months from October 1979 to April 198010 babies developed bullous impetigo. All were full-term infants who had been nursed on the four postnatal wards at this hospital. The lesions developed when the infants were 3 to 8 days old, and in two infants were first noted shortly after discharge from hospital. The lesions were found in a wide variety of sites, particularly the axilla, groin, and neck (figure). In most babies several sites were affected but in no case did the lesions become generalised. Only one baby, who had several large bullae under the axilla, was systemically ill with fever and reluctance to feed.

Cultures, mostly of bullous fluid but otherwise of surface swabs, all grew Staphylococcus aureus, which was resistant to penicillin and sensitive to cloxacillin. Phage types of the strains in nine of the babies were obtained. Six of these belonged to group II. The same phage type was found in three babies, but they had been on two different wards and at different times: the second developed the condition three weeks after the first, and the third four and a half months after the second. The phage types in the remaining six infants were all different. In all, seven different phage types were identified. High vaginal swabs were obtained from eight mothers still resident at the time of diagnosis, and Staph aureus was not cultured from any. No further cases of bullous impetigo have been seen.

Routine care of babies on the postnatal wards includes the daily application of a powder containing $0.33 \%$ hexachlorophane (Sterzac powder) to the umbilicus, and the babies are first bathed with soap on their fifth day. There had been no change in nursing technique in the maternity department before this outbreak.

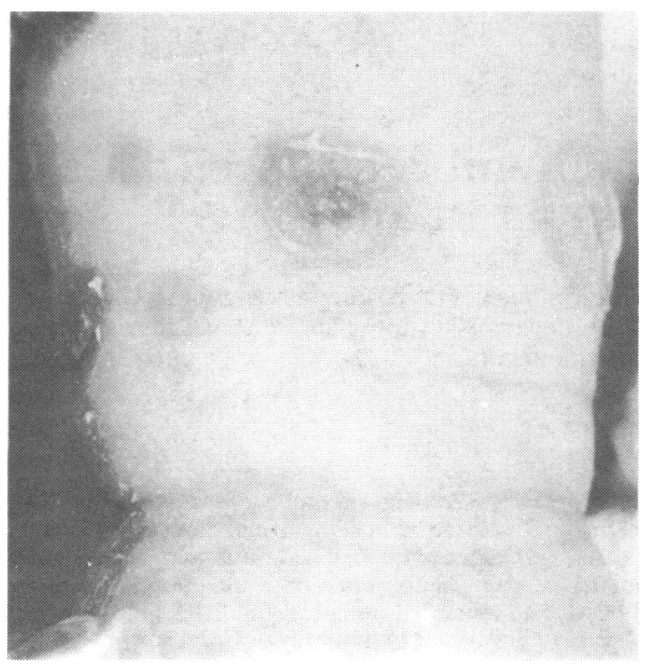

Bullous impetigo on arm of neonate.

After the first four cases had been diagnosed nose swabs were obtained from all the staff. On the sixth day one mother developed a Staph aureus breast abscess and on the eighth day her baby developed bullae infected with the same phage type. The strain in this baby was of the same phage type as that in another born three weeks later but nursed on a different ward. A member of the paediatric staff who had been present at the delivery of the former baby and examined the latter was subsequently found to be a nasal carrier of the same phage type of Staph aureus. Both babies' mothers were 
also nasal carriers. After these cases the importance of diligent hand-washing with chlorhexidine was emphasised and the problem widely discussed. Despite this six further cases occurred.

\section{Comment}

Since the widespread outbreaks of staphylococcal disease in nurseries for newborn babies in the early 1950s and early 1970s outbreaks of bullous impetigo are now rarely seen. Their occurrence depends on the phage type and virulence of the prevalent staphylococci, with bullous impetigo usually caused by organisms of phage group II. Infants are usually colonised from their mothers or by contact with nursing and medical staff, and the incidence of colonisation may be reduced by scrupulous hand-washing before and after handling each infant. Antiseptic baths with hexachlorophane have been withdrawn from routine use in nurseries for the newborn as it is now known to be absorbed through intact skin. Detectable concentrations of hexachlorophane have been recovered from brain tissue in very immature infants who were shown to have a spongioform myelinopathy after repeated bathing. ${ }^{1}$ The daily use of dusting powder containing $0.33 \%$ hexachlorophane may result in a reduction of staphylococcal colonisation $^{2}$ but it is difficult to provide definite evidence that skin preparations are necessary in the newborn. ${ }^{3}$

Seven different strains of Staph aureus were isolated in the outbreak described, and the cases appeared at variable intervals and on several different wards. Rather than being spread from a common source, this was a cluster of cases appearing over a fairly short period. Our experience suggests that staphylococcal bullous impetigo might again create a problem in nurseries for newborn babies.

${ }^{1}$ Anderson JM, Kilshaw BH, Harkness RA, Kelly RW. Spongioform myelinopathy in premature infants. Br Med F 1965 ;ii:175.

2 Gillespie WA, Garner BD, Burman D, Alder VG. Antimicrobial applications for prophylaxis in the newborn. Chemotherapy 1976;3:361

${ }^{3}$ Davies PA. Treatment of neonatal bacterial infection. In: Valman HB, ed. Paediatric therapeutics. Oxford: Blackwell Scientific Publications, 1979 185.

(Accepted 7 September 1981)

Northwick Park Hospital and Clinical Research Centre, Harrow, Middlesex HA1 3UU

T J LISSAUER, MB, MRCP, senior paediatric registrar (now at St Mary's Hospital, London W2)

P J SANDERSON, PHD, MRCPATH, consultant microbiologist (now at Edgware General Hospital, Edgware, Middlesex)

H B VALMAN, MD, FRCP, consultant paediatrician

\section{Pseudomembranous colitis in a 5-week-old infant}

Pseudomembranous colitis has been recognised as a rare complication of giving antibiotics. We report a case that occurred in a 5-week-old infant after amoxycillin.

\section{Case report}

A 5-week-old Asian boy weighing $3000 \mathrm{~g}$ was admitted with a history of fever and refusing feeds. He had had a normal birth at term, weighed $2340 \mathrm{~g}$, and been bottle-fed. Two days before admission he had been prescribed amoxycillin for an upper respiratory tract infection. On admission he was feverish $(39.5 \mathrm{C})$ and irritable but had no localising signs of infection. White cell count was $17.4 \times 10^{9} / 1\left(17400 / \mathrm{mm}^{3}\right)$. Cerebrospinal fluid and blood cultures were sterile; nose and throat swabs grew normal flora; and urine culture showed no appreciable growth.

On the third day of illness he developed bloodstained stools with mucus. $\mathrm{He}$ was given electrolyte solution by mouth, intravenous ampicillin, and intravenous $0.18 \%$ saline in $4 \%$ dextrose solution. Repeated stool cultures failed to grow shigella, salmonella, enteropathogenic Escherichia coli, or campylobacter and were negative for rotavirus (Rotazyme, Abbott Laboratories Ltd). On the fourth day he developed a complete ileus with greatly distended abdomen, and abdominal $x$-ray examination showed dilated bowel loops and multiple fluid levels. There was serious electrolyte disturbance (urea $5.0 \mathrm{mmol} / 1(30 \mathrm{mg} / 100 \mathrm{ml})$, sodium $112 \mathrm{mmol}(\mathrm{mEq}) / 1$, and potassium $8.6 \mathrm{mmol}(\mathrm{mEq}) / \mathrm{l})$, which was resistant to treatment with sodium polystyrene sulphonate enemas and $0.45 \%$ saline in $5 \%$ dextrose drip. Oral fluids were stopped and bile aspirated via a nasogastric tube.

By the fifth day the white cell count had risen to $69 \cdot 6 \cdot 10^{9} / 1\left(69000 / \mathrm{mm}^{3}\right)$ with $88^{\circ} \%$ polymorphornuclear cells and his general condition had deteriorated. Urine output was poor, and $20 \mathrm{ml}$ plasma $/ \mathrm{kg}$ body weight was given intravenously followed by physiological saline. Gentamicin and hydrocortisone were added. Laparotomy was performed, which excluded a surgically treatable condition: it showed massive generalised straw-coloured ascites and externally the whole colon was thickened, inflamed, and oedematous. After operation he continued to deteriorate despite active management including metronidazole. Appreciable metabolic acidosis, recurrent episodes of hypoglycaemia, and sclerema developed, and he died eight days after the onset of illness.

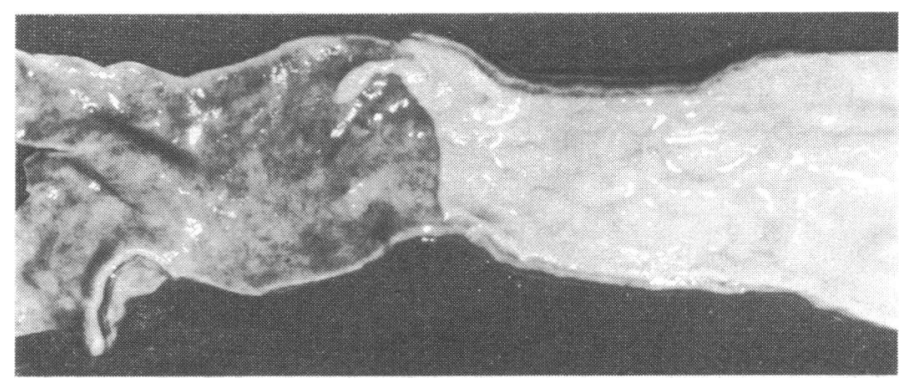

Postmortem specimen of opened large bowel. Pseudomembrane has been removed on the left to show underlying necrotic mucosa.

At necropsy the small bowel was normal but the entire large-bowel mucosa was replaced by a thick bright yellow membrane that separated easily from the submucosa (figure). Histologically the membrane was a fibrinopurulent exudate replacing the mucosa and often the submucosa. Clostridium difficile was isolated from the large-gut contents and neutralisable toxin detected to a titre of $1 / 1000$ in Hep 2 cells.

\section{Comment}

Many antibiotics have been associated with pseudomembranous colitis. Larson $e^{t}$ al ${ }^{1}$ suggested that the colitis is caused by $C$ difficile and an associated toxin. They found, however, that five of eight healthy neonates had $C$ difficile in their stools and two also had toxin. In a retrospective study Rietra $e t a l^{2}$ found a cytotoxic effect in $14 \%$ of stool samples from infants aged up to 5 months. Donta $e t \mathrm{al}^{3}$ described pseudomembranous colitis in a neonate beginning within three days of a course of ampicillin.

A Scandinavian survey ${ }^{4}$ of 218 children aged 2 weeks to 15 years found toxigenic $C$ difficile in $43(20 \%)$ but in only two out of 49 children aged under 1 month. We examined the faeces of 35 children aged under 1 month. $C$ difficile was isolated from 11 (only two had received antibiotics) and none produced toxin in culture filtrates or the faeces. Thus the exact importance of $C$ difficile and its toxin in the bowel of neonates and young infants is still not fully understood.

Our infant was initially well apart from fever but deteriorated steadily after receiving oral amoxycillin. We then used intravenous ampicillin when blood and mucus appeared in the stool, thinking that the infant had dysentery. This calls into question the generous use of antibiotics previously thought to be relatively harmless. Cases of pseudomembranous colitis not associated with antibiotics have been described, and there may be other factors to take into account.

${ }^{1}$ Larson HE, Price AB, Honour P, Borriello SP. Clostridium difficile and the aetiology of pseudomembranous colitis. Lancet 1978;i:1063-6.

2 Rietra PJGM, Slaterus KW, Zanen HC, Meuwissen SGM. Clostridial toxin in faeces of healthy infants. Lancet 1978;ii:319.

${ }^{3}$ Donta ST, Stuppy MS, Myers MG. Neonatal antibiotic-associated colitis. Am $\mathcal{F}$ Dis Child $1981 ; \mathbf{1 3 5}: 181-2$.

1 Holst E, Helin I, Mardh P-A. Recovery of Clostridium difficile from children. Scand $\mathcal{f}$ Infect Dis $1981 ; 13: 41-5$.

(Accepted 8 September 1981)

\section{City General Hospital, Stoke-on-Trent}

S A RICHARDSON, $\mathrm{MB}, \mathrm{DCH}$, registrar in paediatrics

D S K BROOKFIELD, MB, MRCP, consultant paediatrician

North Staffordshire Central Pathology Laboratory, Stoke-on-Trent T A FRENCH, MB, MRCPATH, consultant pathologist J GRAY, MRCPATH, DIPBACT, deputy director of public health laboratory 